\title{
Effect of electromagnetic fields and antioxidants on the trace element content of rat teeth
}

This article was published in the following Dove Press journal:

Drug Design, Development and Therapy

4 May 2017

Number of times this article has been viewed

\author{
Mehmet Sinan Dogan' \\ Mehmet Cihan Yavas ${ }^{2}$ \\ Yasemin Yavuz ${ }^{3}$ \\ Sait Erdogan ${ }^{4}$ \\ İsmail Yener ${ }^{4}$ \\ İbrahim Simsek' \\ Zeki Akkus ${ }^{5}$ \\ Veysel Eratilla ${ }^{6}$ \\ Abdulsamet Tanik ${ }^{7}$ \\ Mehmet Zulkuf Akdag ${ }^{2}$ \\ 'Department of Pediatric Dentistry, \\ Faculty of Dentistry, Harran \\ University, Șanlıurfa, ${ }^{2}$ Department \\ of Biophysics, Faculty of Medicine, \\ ${ }^{3}$ Department of Restorative Dentistry, \\ Faculty of Dentistry, ${ }^{4}$ Department \\ of Chemistry, Faculty of Science, \\ ${ }^{5}$ Department of Biostatistics, \\ Faculty of Medicine, ${ }^{6}$ Department \\ of Prosthodontics, ${ }^{7}$ Department of \\ Periodontology, Faculty of Dentistry, \\ Dicle University, Diyarbakir, Turkey
}

Correspondence: Mehmet Sinan Dogan Department of Pediatric Dentistry,

Faculty of Dentistry, Harran University, Șanlıurfa 63300, Turkey

Email dtlider@hotmail.com

\begin{abstract}
The purpose of this study was to examine the possible effect of extremely low-frequency electromagnetic fields (ELF-EMFs), from a high-voltage source, on rat teeth in terms of changes in trace elements (TEs) and the effect of antioxidants (melatonin [MLT] and Ganoderma lucidum [GL]) in counteracting these effects. We used adult male Wistar albino rats with a mean weight of 250-300 $\mathrm{g}$ and divided the rats into eight groups. The groups were subjected to an ELF-EMF that was applied with a high-voltage line for 8 hours/day for 26 days (Groups I, II, and III) or 52 days (Groups V, VI, and VII). Groups IV and VIII were the 26- and 52-day control/sham groups, respectively. Groups II and VI were treated with GL, and Groups III and VII were treated with MLT. MLT and GL were administered daily based on the weight of the animals and appropriate standards. At the end of the study, the rats were euthanized, and their anterior teeth were extracted. The teeth were preserved in pure water before evaluating the major TEs. At the end of the study, TE concentrations (in $\mathrm{mg} / \mathrm{kg}$ ) were assessed in the control and test groups. Compared with Group V, statistically significant differences in the concentrations of zinc ( $\mathrm{Zn}$ ) and strontium ( $\mathrm{Sr}$ ) were found for Group VII (ELF-EMF + MLT) $(P<0.05)$. Therefore, ELF-EMF exposure can change the content of certain TEs in teeth and, after administering MLT and GL, the values of some of the TEs return to normal.
\end{abstract}

Keywords: ELF-EMF, tooth, trace element, melatonin, Ganoderma lucidum

\section{Introduction}

Recently, in both the workplace and the home, the usage of devices creating low- and medium-frequency electromagnetic fields (EMFs) has increased. ${ }^{1}$ EMF causes harmful effects on human health. Exposure to EMF affects neural networks, body weight, tissue morphology and histology, biochemical parameters of the blood, hormones, the immune system, and the tissue repair system. ${ }^{2}$ The modifications caused by EMF to cells and molecules depend on the length of the exposure, penetration, and the healing ability of the tissue. ${ }^{3}$ The EMFs created in home environments also have some negative effects such as leukemia and tumor formation in the central neural system. ${ }^{4}$

It has been determined that low-frequency EMF affects the cellular antioxidant defense mechanisms, which increases oxidative damage and causes DNA damage, thereby resulting in a carcinogenic effect. ${ }^{5-7}$ In addition, exposure to EMFs caused by mobile phones is reported to lead to lack of attention, damage in the inner ear, reduction of the speed of reflexes, blurred vision, and headaches. ${ }^{8}$ It is reported that high-frequency EMF has a genotoxic impact on tissues. ${ }^{9}$

Exposure to EMFs depresses melatonin (MLT; $N$-acetyl-5-methoxytryptamine) production in the pineal gland. MLT is an endogenous hormone that is released into the blood from the pineal gland. ${ }^{10}$ It stimulates the release of antioxidant enzymes and releases free radicals that are formed in the body. ${ }^{11}$ Reductions in MLT production 
increase the risk of cancer. ${ }^{12-14}$ The level of serum MLT is reflected in the level of MLT in the saliva. The level of MLT in the saliva is one-quarter of the level of MLT in the body. ${ }^{11}$ In addition, a type of fungi known as Ganoderma lucidum (GL) is effective for the prevention of free radical production and for the treatment of hypertension, diabetes, hepatitis, cancer, and human immunodeficiency virus (HIV) infections. ${ }^{15}$

Studies conducted on animals have demonstrated a relationship between exposure to EMFs, free radical production, and cancer formation. ${ }^{10}$ It has been reported that free radical production and tumor formation decrease when MLT is given to animals exposed to EMF under experimental conditions. ${ }^{10}$

EMFs also affect the balance of liquids and electrolytes and the concentration of trace elements (TEs). ${ }^{16}$ TEs play an important role in human health. The lack or abundance of TEs can have toxic effects. ${ }^{17}$ Measuring TE concentrations using tissue samples is critical in order to deduce these toxic effects and subsequently correct them. Generally, in TE studies, tissue samples such as blood, urine, tooth, nail, and hair are used.

In addition, teeth are reported to be a suitable indicator of overall TE concentrations. ${ }^{17,18}$ TEs are found at different concentrations in the tooth enamel. Changes in the density of some TEs affect the health of teeth and general human health. Some elements may cause tooth decay. The relationship between the concentrations of elements such as calcium $(\mathrm{Ca})$, zinc $(\mathrm{Zn})$, phosphorus $(\mathrm{P})$, and magnesium $(\mathrm{Mg})$ in the structure of decaying teeth has been reported. ${ }^{17}$ Fluorine (F) and phosphorus (P) are elements that prevent tooth decay, whereas selenium (Se), magnesium $(\mathrm{Mg})$, cadmium $(\mathrm{Cd})$, platinum $(\mathrm{Pt})$, lead $(\mathrm{Pb})$, and silicon $(\mathrm{Si})$ can cause tooth decay. ${ }^{17}$

$\mathrm{Mg}$ is a key element for the functioning of important biological polyphosphate compounds, such as ATP, DNA, and RNA. Mg is also used in the mineralization of teeth and bones. $\mathrm{Ca}^{2+}$ is a key factor for neurotransmitter secretion, oxidative stress, and apoptosis. $\mathrm{Zn}$ is necessary for DNA synthesis, RNA transcription, cell division, and cell activation. Copper $(\mathrm{Cu})$ is an essential component of the respiratory enzyme complex, cytochrome c oxidase. $\mathrm{Zn}$ and $\mathrm{Cu}$ play protective roles against oxidation by acting as cofactors for antioxidant enzymes. Iron (Fe) plays an essential role by combining with oxygen molecules in hemoglobin and myoglobin. Se is found combined with several antioxidant enzymes such as glutathione peroxidase and thioredoxin reductase. Manganese $(\mathrm{Mn})$ is necessary for the regulation of blood sugar and cellular energy levels, immune system functioning, bone growth, defense against free radicals, and blood coagulation (along with vitamin K). ${ }^{19}$

The impact of EMFs on TEs in enamel and dentin can be explained by the changes that they induce in chemical binding exhibited by TEs. ${ }^{20}$ The purpose of this study was to examine the impact of extremely low-frequency (ELF) EMFs, from a high-voltage source, on TE concentrations in rat teeth. In addition, the impact of MLT and GL on the unwanted effects of the EMFs was also evaluated.

\section{Materials and methods}

This study was performed at the Prof Dr Sabahattin Payzin Health Sciences Research and Application Center at Dicle University, Diyarbakır, Turkey. All animal procedures were conducted in accordance with the Principles of Laboratory Animal Care and the rules of the Scientific and Ethics Committee of Dicle University Health Research Center (ethics committee approval no: 2013/13).

Adult male Wistar albino rats with a mean weight of 250 $300 \mathrm{~g}$ were used in this study. After a 1-week adaptation period, the rats were randomly divided into eight groups. These groups were treated as follows: Group I: 26 days of high-voltage ELFEMF exposure; Group II: 26 days of high-voltage ELF-EMF exposure + GL; Group III: 26 days of high-voltage ELF-EMF exposure + MLT; Group IV: control/sham group for 26 days; Group V: 52 days of high-voltage ELF-EMF exposure; Group VI: 52 days of high-voltage ELF-EMF exposure + GL; Group VII: 52 days of high-voltage ELF-EMF exposure + MLT; and Group VIII: control/sham group for 52 days.

To produce the ELF-EMF, two transformers were used, which produced a high-voltage EMF (up to $10 \mathrm{kV}$ was used). For transformer 1, the input was $220 \mathrm{~V}$ and the output was $10 \mathrm{kV}$. For transformer 2, the input was $10 \mathrm{kV}$ and the output was $220 \mathrm{~V}$. The rats in both the 26-day and the 52-day experimental groups (Groups I, II, III, V, VI, and VII) were exposed to ELF-EMF for 8 hours/ day. We measured the mean magnetic field intensity $(2.48 \mu \mathrm{T})$ and the electric field strength $(80.3 \mathrm{~V} / \mathrm{m})$ in the Plexiglas cages. The EMF was measured with the aid of a Spectran device NF5035 (AARONIA AG, Strickscheid, Germany), using the 6-minute measurement method (International Commission for Non-Ionizing Radiation Protection [ICNIRP]).

MLT and GL were prepared according to the weight of the animals and appropriate standards. For each rat in the two MLT groups, $10 \mathrm{mg} / \mathrm{kg}$ MLT (Merck KGaA, Darmstadt, Germany) was dissolved in pure ethanol and then diluted with distilled water. The MLT was then administered intraperitoneally on a daily basis. For each rat in the two 
GL groups, 20 mg/kg GL (Gano Excel Industries Sdn. Bhd., Kedah, Malaysia) was prepared (by dilution with distilled water) and administered by oral gavage. At the end of the study, the rats underwent anesthesia ( $0.1 \mathrm{cc}$ xylazine $+0.9 \mathrm{cc}$ ketamine per rat). Then, the rats were sacrificed by intracardiac lethal injection and exsanguination euthanasia, and their anterior teeth were extracted. To preserve their quality, the teeth samples were stored at ambient temperature in sealed plastic bags prior to processing.

\section{Microwave digestion}

All teeth samples were washed with water and then dried in an oven at $65^{\circ} \mathrm{C}$. All the samples weighed between $0.2 \mathrm{~g}$ and $0.5 \mathrm{~g}$ (according to precise measurement in a Teflon vessel) prior to being digested with $6 \mathrm{~mL}$ of concentrated ultrapure nitric acid $(65 \%)$ and $2 \mathrm{~mL}$ of ultrapure hydrogen peroxide $(30 \%)$. The acid digestion of the teeth samples was performed using a commercial high-pressure laboratory microwave oven (Ethos One; Milestone Srl - Via Fatebenefratelli 1/5, 24010 Sorisole (BG), Italy). For each sample, a one-step microwave program was used, increasing for 15 minutes to $200^{\circ} \mathrm{C}$ at $1,000 \mathrm{~W}$ and maintenance at $200^{\circ} \mathrm{C}$ and $1,000 \mathrm{~W}$ for 10 minutes. Any undissolved material was removed with filtered $25 \mathrm{~mm}$ polyethylene syringes.

\section{Instruments}

An inductively coupled plasma mass spectrometry (ICP-MS) system (model 7700X; Agilent, Santa Clara, CA, USA) was used for the simultaneous detection of $\mathrm{Li}, \mathrm{B}, \mathrm{Mg}, \mathrm{Ca}, \mathrm{V}, \mathrm{Mn}$, $\mathrm{Fe}, \mathrm{Co}, \mathrm{Zn}, \mathrm{As}$, Se, strontium ( $\mathrm{Sr}$ ), Ag, Cd, Pb, and $\mathrm{P}$.

\section{Reagents and solutions}

The nitric acid (Merck) and hydrogen peroxide (Merck) were analytical-grade reagents. Ultrapure water was used in all the experiments.

\section{Statistics}

The between-group differences in the experimental data were compared statistically. For this purpose, Mann-Whitney $U$ and Wilcoxon signed-rank tests were used.

\section{Results}

At the end of the study, the concentrations (in $\mathrm{mg} / \mathrm{kg}$ ) of $\mathrm{Li}$, $\mathrm{B}, \mathrm{Mg}, \mathrm{Ca}, \mathrm{V}, \mathrm{Mn}, \mathrm{Fe}, \mathrm{Co}, \mathrm{Zn}, \mathrm{As}, \mathrm{Se}, \mathrm{Sr}, \mathrm{Ag}, \mathrm{Cd}, \mathrm{Pb}$, and $\mathrm{P}$ were obtained from the control and test groups, as shown in Table 1. Compared with the value of other TEs, according to the Mann-Whitney $U$ test, the concentrations of $\mathrm{Sr}$ and Zn displayed significant differences $(P<0.05)$.

In Group I, the concentrations of Li, B, Zn, As, V, Cd, Pb, and $\mathrm{Se}$ increased, and the concentrations of $\mathrm{Mg}, \mathrm{Fe}, \mathrm{Co}, \mathrm{Ca}$, and $\mathrm{P}$ decreased. However, in Group V, the concentrations of $\mathrm{Li}, \mathrm{As}$, and Se increased, and the concentrations of $\mathrm{B}, \mathrm{Ca}$, $\mathrm{Mn}, \mathrm{Co}, \mathrm{V}, \mathrm{Sr}, \mathrm{Cd}$, and $\mathrm{Pb}$ decreased.

In Group II, GL returned the concentrations of $\mathrm{Li}, \mathrm{B}, \mathrm{Mg}$, $\mathrm{Ca}, \mathrm{Fe}, \mathrm{Zn}, \mathrm{As}, \mathrm{P}$, and Se to the levels in the 26-day control group. In Group III, MLT returned the concentrations of $\mathrm{B}, \mathrm{Mg}, \mathrm{Ca}, \mathrm{Fe}, \mathrm{Zn}, \mathrm{V}, \mathrm{Cd}, \mathrm{Pb}, \mathrm{P}$, and Se to the levels in the 26-day control group.

In Group VI, GL returned the concentrations of $\mathrm{Co}, \mathrm{V}$, and Se to the approximate concentrations in the 52-day control group. In Group VII, MLT returned the concentrations of Li,

Table I TE contents in each group at the end of the study

\begin{tabular}{|c|c|c|c|c|c|c|c|c|}
\hline TE (mg/kg) & Group I & Group II & Group III & Group IV & Group V & Group VI & Group VII & Group VIII \\
\hline${ }^{7} \mathrm{Li}$ & 0.2617 & 0.1695 & 0.0834 & 0.1693 & 0.1735 & 0.1013 & 0.1495 & 0.1443 \\
\hline "B & 0.0417 & 0.0277 & 0.0275 & 0.0264 & 0.0216 & 0.0187 & 0.0166 & 0.0352 \\
\hline${ }^{24} \mathrm{Mg}$ & 0.6803 & 0.8939 & $0.88 \mid 4$ & 0.8768 & 0.8505 & 0.8191 & 0.7801 & 0.8464 \\
\hline${ }^{44} \mathrm{Ca}$ & 0.4895 & 0.5342 & 0.5240 & 0.5767 & 0.5436 & 0.5537 & 0.5624 & 0.6148 \\
\hline${ }^{55} \mathrm{Mn}$ & 0.0015 & 0.0018 & 0.0013 & 0.0016 & 0.0013 & 0.0012 & 0.0013 & 0.0016 \\
\hline${ }^{56} \mathrm{Fe}$ & 0.1330 & 0.2026 & 0.2493 & 0.2606 & 0.2645 & 0.2587 & 0.2358 & 0.2518 \\
\hline${ }^{59} \mathrm{Co}$ & 0.0061 & 0.0088 & 0.0042 & 0.0074 & 0.0031 & 0.0053 & 0.0065 & 0.0050 \\
\hline${ }^{66} \mathrm{Zn}$ & 0.0682 & 0.0532 & 0.0585 & 0.0550 & 0.0616 & 0.0991 & 0.1775 & 0.1335 \\
\hline${ }^{75} \mathrm{As}$ & 0.0859 & 0.0402 & 0.0000 & 0.0310 & 0.0215 & 0.1174 & $0.044 I$ & 0.0094 \\
\hline${ }^{51} \mathrm{~V}$ & 0.1041 & 0.1001 & 0.0494 & 0.0683 & 0.0325 & 0.0715 & 0.0911 & 0.0765 \\
\hline${ }^{88} \mathrm{Sr}$ & 0.1473 & 0.1215 & 0.1322 & 0.1422 & 0.1632 & 0.1663 & 0.1735 & 0.1816 \\
\hline${ }^{107} \mathrm{Ag}$ & 0.0013 & 0.0012 & 0.0011 & 0.0011 & 0.0010 & 0.0012 & 0.0011 & 0.0012 \\
\hline${ }^{\prime \prime} \mathrm{Cd}$ & 0.0042 & 0.0096 & 0.0017 & 0.0013 & 0.0029 & 0.0018 & 0.0038 & 0.0056 \\
\hline${ }^{208} \mathrm{~Pb}$ & 0.1166 & 0.1688 & 0.0820 & 0.0861 & 0.0810 & 0.0967 & 0.1156 & 0.1258 \\
\hline${ }^{15} \mathrm{P}$ & 0.6900 & 0.9770 & 0.9470 & 0.8200 & 0.9130 & 0.8170 & 0.8620 & 0.9840 \\
\hline${ }^{78} \mathrm{Se}$ & 0.2016 & 0.0534 & 0.0472 & $0.04 \mathrm{II}$ & 0.3113 & 0.1167 & 0.1120 & 0.1524 \\
\hline
\end{tabular}

Notes: Group I, 26 days of high-voltage ELF-EMF exposure; Group II, 26 days of high-voltage ELF-EMF exposure + GL; Group III, 26 days of high-voltage ELF-EMF exposure + MLT; Group IV, control/sham group for 26 days; Group V, 52 days of high-voltage ELF-EMF exposure; Group VI, 52 days of high-voltage ELF-EMF exposure + GL; Group VII, 52 days of high-voltage ELF-EMF exposure + MLT; and Group VIII, control/sham group for 52 days.

Abbreviation: TE, trace element. 
$\mathrm{Ca}, \mathrm{V}, \mathrm{Cd}, \mathrm{Pb}$, and $\mathrm{Se}$ to the approximate concentrations in the 52-day control group. The concentrations of Ag in the various groups changed very little.

\section{Discussion}

EMFs affect a wide area, and they can be caused by low and high currents. Due to the development of electromagnetic technology, EMFs are now widely used in various fields, including military applications, medical devices, and security systems. Concerns regarding the hazardous biological effects of EMFs on human health are on the rise. ${ }^{19}$

High-frequency magnetic fields affect superficial tissues, whereas it is reported that low-frequency magnetic fields have hazardous impacts on deeper tissues. ${ }^{21}$ The impact of magnetic fields on cellular functions has been examined, and damage to DNA, the production of oxidation products, and effects on intracellular $\mathrm{Ca}^{2+}$ signals have been found. ${ }^{22}$ Exposure to EMFs affects the formation of free radicals and some elements. Lack or abundance of certain metals leads to multiple clinical impacts. A previous study conducted on rats exposed to EMFs found that the $\mathrm{Zn}$ plasma concentration increased while the Fe concentration decreased. ${ }^{22}$ In this study, a statistically significant difference was found in the concentration of $\mathrm{Zn}$ in Groups I and V and, after antioxidant usage (MLT or GL), the $\mathrm{Zn}$ concentration approximated that in the control group. In addition, it was found that high-voltage ELF-EMFs increased the concentrations of $\mathrm{Li}, \mathrm{B}$, and Se and decreased the concentrations of $\mathrm{Mg}, \mathrm{Ca}$, and $\mathrm{Fe}$. The values returned to normal after administering an antioxidant (MLT or GL).

Another animal study of EMFs reported that they affect the liquid and electrolyte balance. ${ }^{16}$ At the same time, EMFs also affect the concentration of some TEs and the electrolyte balance $\left(\mathrm{Na}^{+}, \mathrm{K}^{+}, \mathrm{Ca}^{++}\right.$, and $\left.\mathrm{Mg}^{++}\right)$. Lack or abundance of TEs also causes toxic effects. ${ }^{17}$ There are several TEs in the calcified tissue of the teeth. Measurements showing lack or abundance of TEs provide information about diseases. The causes of decayed/healthy tooth structure can be understood in terms of decreases in matrix elements such as $\mathrm{Ca}$ and $\mathrm{P}$ and increases in non-matrix elements such as $\mathrm{Sr}, \mathrm{Na}, \mathrm{K}, \mathrm{Mg}, \mathrm{Zn}$, and C. ${ }^{23,24}$ In this study, the impact of EMFs and antioxidants on the TE concentrations in rat teeth was examined.

In order to deduce and subsequently correct these impacts, it is important to measure the TE concentrations using a tissue sampling method. Generally, in TE studies, tissue samples such as blood, urine, nail, and hair samples are used. Nevertheless, teeth have also been reported to be suitable indicators of overall TE concentrations, as teeth consist of a diverse range of elements, and the concentrations of these elements are affected by overall TE concentrations in the body. ${ }^{17,18}$
TEs are found at different concentrations in the tooth enamel. Previous studies have reported the relationship between elements such as $\mathrm{Ca}, \mathrm{Zn}, \mathrm{P}$, and $\mathrm{Mg}$ in decaying teeth. ${ }^{21,24}$ In addition, lack of $\mathrm{Zn}$ causes reductions in thrombocyte aggregation, $\mathrm{T}$ lymphocyte concentrations, and the levels of phytomitogene. ${ }^{25} \mathrm{Zn}$ plays an essential role as a structural, catalytic, and regulatory factor in biological organisms. In addition, $\mathrm{Zn}$ ensures that cells are protected from oxidative stress. ${ }^{25}$ In our study, the level of $\mathrm{Zn}$ in the teeth of rats exposed to EMFs for 52 days was lower than the level in the 52-day control group, and the $\mathrm{Zn}$ level in the groups that were treated with an antioxidant (MLT or GL) increased only compared to the group exposed to EMFs. In addition, according to Groups VII-VIII, in the teeth of rats exposed to EMFs for 52 days, there was a significant decrease in the level of $\mathrm{Zn}(P<0.05)$.

Exposure to EMFs affects the functions of biological systems due to increases in oxidative stress. ${ }^{26} \mathrm{~A}$ previous study examined the impact of magnetic field exposure on oxidative stress created by EMFs and identified protective impacts. ${ }^{27}$ In our study, we found that treatment with an antioxidant (MLT or GL) caused the TE concentrations (that were changed by high-voltage ELF-EMFs) to return to their normal values.

$\mathrm{Zn}$ is both an antioxidant and a factor involved in the structure of superoxide dismutase. Oxidative stress (which can increase after repeated infections and surgical operations) creates an increased metabolic demand for antioxidants. ${ }^{25,28}$ For this reason, the $\mathrm{Zn}$ concentration in the body decreases. ${ }^{28}$ In our study, the concentration of $\mathrm{Zn}$ increased after 26 days of exposure to high-voltage ELF-EMFs (Group I), and 52 days of exposure to high-voltage ELF-EMFs decreased the concentration of $\mathrm{Zn}$ (Group V). In addition, the $\mathrm{Zn}$ concentration was found to return to normal after usage of antioxidants (MLT or GL) in Groups II, III, and VII.

Living organisms are constantly being exposed to natural geomagnetic fields ranging between 20 and $70 \mu \mathrm{T}$. Previous studies have shown that EMFs increase the concentration of reactive oxygen products and cause pro-inflammatory changes in biological systems. Magnetic field exposure (128 $\mathrm{mT}$ for 1 hour/day for 5 days) has been found to decrease the amount of Se in the kidneys, muscles, and brain and decrease glutathione peroxidase activity in the kidneys and muscles. ${ }^{29}$ In our study, no statistically significant difference was found in terms of the Se levels. However, numerically, the concentration of Se increased in Groups I and V.

In a previous study conducted in rats, TE concentrations in the serum were examined. ${ }^{22}$ No significant change was found in the ratio of $\mathrm{Na}, \mathrm{K}, \mathrm{Ca}, \mathrm{P}$, and $\mathrm{Se}$ in the serum. In contrast, an increase in the $\mathrm{Zn}$ ratio and a decrease in the 
Fe concentration were found. Lack or abundance of these TEs can lead to clinical impacts. ${ }^{22}$ In our study, although a statistically significant change was not observed in the level of Fe, in terms of numerical values, the Fe level returned to normal in the group exposed to ELF-EMF for 26 days after treatment with an antioxidant (MLT or GL).

In another study, it was found that serum $\mathrm{Na}, \mathrm{K}, \mathrm{Mg}$, $\mathrm{Ca}, \mathrm{Zn}, \mathrm{Cu}, \mathrm{Fe}, \mathrm{Se}$, and $\mathrm{Mn}$ values in rats exposed to electrical fields of 50,100 , and $200 \mathrm{kV} / \mathrm{m}$ for 48 hours remained unchanged. ${ }^{19} \mathrm{~A}$ further study conducted on rats examined the impact of a $2.45 \mathrm{GHz}$ Wi-Fi-induced EMF on teeth, and the study found that the development of rat teeth and surrounding tissues was not affected by $2.45 \mathrm{GHz}$ Wi-Fi. In addition, no statistically significant differences were found in the concentrations of $\mathrm{Ca}, \mathrm{K}, \mathrm{Mg}, \mathrm{Na}, \mathrm{P}$, or $\mathrm{Cd}$ in the rat teeth. ${ }^{30}$ However, the concentrations of $\mathrm{Zn}, \mathrm{Ag}$, and $\mathrm{B}$ decreased and the concentrations of $\mathrm{Fe}$ and $\mathrm{Sr}$ increased. ${ }^{30}$ In our study, an increase was detected in the concentration of $\mathrm{B}$ in rat teeth exposed to ELF-EMF for 26 days (Group I).

It has been reported that $\mathrm{Se}, \mathrm{Mg}, \mathrm{Cd}, \mathrm{Pt}$, and $\mathrm{Pb}$ are carcinogenic, while $\mathrm{F}$ and $\mathrm{K}$ are cariostatic. ${ }^{31}$ In our study, as a result of exposure to 26 days of high-voltage ELF-EMFs, an increase was found in the concentrations of $\mathrm{Se}, \mathrm{Cd}$, and $\mathrm{Pb}$ and a decrease was detected in the concentration of $\mathrm{K}$ (compared to the 26-day control/sham group).

\section{Conclusion}

The data showed that exposure to high-voltage ELF-EMFs causes changes in TE concentrations in rat teeth. Increases and decreases in TE concentrations can have toxic effects on human health. There were changes in the values of cariogenic elements such as $\mathrm{Se}, \mathrm{Mg}, \mathrm{Cd}$, and $\mathrm{Pb}$. ELF-EMFs increased the values of $\mathrm{Se}, \mathrm{Cd}, \mathrm{Pb}$, and $\mathrm{Mn}$. The use of antioxidants, especially MLT, was found to reduce these values to their normal levels. However, we believe that further epidemiological, histological, and chemical studies should be conducted in this area.

\section{Acknowledgement}

The authors declare that there were no other contributors involved in this work.

\section{Disclosure}

The authors report no conflicts of interest in this work.

\section{References}

1. Sullivan K, Balin AK, Allen RG. Effects of static magnetic fields on the growth of various types of human cells. Bioelectromagnetics. 2011; 32(2):140-147.
2. Oksay T, Naziroglu M, Dogan S, Guzel A, Gumral N, Kosar P. Protective effects of melatonin against oxidative injury in rat testis induced by wireless (2.45 GHz) devices. Andrologia. 2014;46(1):65-72.

3. Franzellitti S, Valbonesi P, Ciancaglini N, et al. Transient DNA damage induced by high-frequency electromagnetic fields (GSM $1.8 \mathrm{GHz}$ ) in the human trophoblast HTR-8/SVneo cell line evaluated with the alkaline comet assay. Mutat Res. 2010;683(1-2):35-42.

4. Kameda T, Ohkuma K. Electromagnetic fields from dental devices and their effects on human health. J Electr Electron Syst. 2014;3(1):1-6.

5. Wolf FI, Torsello A, Tedesco B, et al. 50-Hz extremely low frequency electromagnetic fields enhance cell proliferation and DNA damage: possible involvement of a redox mechanism. Biochim Biophys Acta. 2005;1743(1-2):120-129.

6. Fitzsimmons RJ, Gordon SL, Kronberg J, Ganey T, Pilla AA. A pulsing electric field (PEF) increases human chondrocyte proliferation through a transduction pathway involving nitric oxide signaling. J Orthop Res. 2008;26(6):854-859.

7. Focke F, Schuermann D, Kuster N, Schär P. DNA fragmentation in human fibroblasts under extremely low frequency electromagnetic field exposure. Mutat Res. 2010;683(1-2):74-83.

8. Colak C, Parlakpinar H, Ermis N, et al. Effects of electromagnetic radiation from $3 \mathrm{G}$ mobile phone on heart rate, blood pressure and $\mathrm{ECG}$ parameters in rats. Toxicol Ind Health. 2012;28(7):629-638.

9. Cervellati F, Franceschetti G, Lunghi L, et al. Effect of high-frequency electromagnetic fields on trophoblastic connexins. Reprod Toxicol. 2009;28(1):59-65.

10. Tranfo G, Pigini D, Brugaletta V, et al. Measures of melatonin and cortisol variations in volunteers exposed to GSM cellular phones in a double blind experiment. Webmedcentral Environ Med. 2010; 1(9): $1-25$

11. Reiter R, Rosales-Corral S, Liu X, Acuna-Castroviejo D, Escames G, Tan D. Melatonin in the oral cavity: physiological and pathological implications. J Periodontal Res. 2015;50(1):9-17.

12. Naziroğlu M, Tokat S, Demirci S. Role of melatonin on electromagnetic radiation-induced oxidative stress and $\mathrm{Ca} 2+$ signaling molecular pathways in breast cancer. J Recept Signal Transduct Res. 2012;32(6):290-297.

13. Dyche J, Anch A, Fogler K, Barnett D, Thomas C. Effects of power frequency electromagnetic fields on melatonin and sleep in the rat. Emerg Health Threats. 2012;5:1-8.

14. Vanderstraeten J, Verschaeve L, Burda H, Bouland C, de Brouwer C. Health effects of extremely low-frequency magnetic fields: reconsidering the melatonin hypothesis in the light of current data on magnetoreception. J Appl Toxicol. 2012;32(12):952-958.

15. Paterson RR. Ganoderma - a therapeutic fungal biofactory. Phytochemistry. 2006;67(18):1985-2001.

16. ŁOpucki M, Czekierdowski A, Rogowska W, Kotarski J. The effect of oscillating low intensity magnetic field on the $\mathrm{Na}+, \mathrm{K}+, \mathrm{Ca}++$, and $\mathrm{Mg}++$ concentrations in the maternal and fetal circulation of the dually perfused human placental cotyledon. Bioelectromagnetics. 2004; 25(5):329-337.

17. Brown CJ, Chenery SR, Smith B, et al. Environmental influences on the trace element content of teeth - implications for disease and nutritional status. Arch Oral Biol. 2004;49(9):705-717.

18. Rao KS, Anupama PM, Mahesh DG, Rao RV, Rautray TR, Venkateswarulu P. Trace elemental analysis of dental caries in human teeth by external PIXE. Int J Appl Biol Pharm Tech. 2010;1(1):68-78.

19. Li K, Ma S, Ren D, et al. Effects of electromagnetic pulse on serum element levels in rat. Biol Trace Elem Res. 2014;158(1):81-86.

20. Kaya S, Akdag MZ, Yavuz I, et al. ELF electromagnetic field and strontium ranilate influences on the trace element content of rat teeth. J Anim Vet Adv. 2009;8:322-327.

21. Ince B, Akdag Z, Bahsi E, et al. Can exposure to manganese and extremely low frequency magnetic fields affect some important elements in the rat teeth? Eur Rev Med Pharmacol Sci. 2012;16(6):763-769.

22. Aida L, Soumaya G, Myriam E, Mohsen S, Hafedh A. Effects of static magnetic field exposure on plasma element levels in rat. Biol Trace Elem Res. 2014;160(1):67-72. 
23. Singh V, Rai A. Potential of laser-induced breakdown spectroscopy for the rapid identification of carious teeth. Lasers Med Sci. 2011;26(3): 307-315.

24. Brown CJ, Chenery SR, Smith B, et al. A sampling and analytical methodology for dental trace element analysis. Analyst. 2002;127(2): 319-323.

25. Chasapis C, Loutsidou A, Spiliopoulou C, Stefanidou M. Zinc and human health: an update. Arch Toxicol. 2012;86(4):521-534.

26. Yilmaz A, Yilmaz N, Serarslan Y, et al. The effects of mobile phones on apoptosis in cerebral tissue: an experimental study on rats. Eur Rev Med Pharmacol Sci. 2014;18(7):992-1000.

27. Liu DD, Ren Z, Yang G, Zhao Q, Mei Y. Melatonin protects rat cerebellar granule cells against electromagnetic field-induced increases in $\mathrm{Na}+$ currents through intracellular $\mathrm{Ca} 2+$ release. J Cell Mol Med. 2014;18(6):1060-1070.
28. Cunha S, Gonçalves G, Marchini J, Roselino A. Acrodermatitis due to zinc deficiency after combined vertical gastroplasty with jejunoileal bypass: case report. Sao Paulo Med J. 2012;130(5):330-335.

29. Ghodbane S, Lahbib A, Sakly M, Abdelmelek H. Bioeffects of static magnetic fields: oxidative stress, genotoxic effects, and cancer studies. Biomed Res Int. 2013;2013:1-12.

30. Çiftçi Z, Kırzıoğlu Z, Nazıroğlu M, Özmen Ö. Effects of prenatal and postnatal exposure of Wi-Fi on development of teeth and changes in teeth element concentration in rats. Biol Trace Elem Res. 2015; 163(1-2):193-201.

31. Shashikiran N, Subba Reddy V, Hiremath M. Estimation of trace elements in sound and carious enamel of primary and permanent teeth by atomic absorption spectrophotometry: an in vitro study. Indian J Dent Res. 2007;18(4):157-162.

\section{Publish your work in this journal}

Drug Design, Development and Therapy is an international, peerreviewed open-access journal that spans the spectrum of drug design and development through to clinical applications. Clinical outcomes, patient safety, and programs for the development and effective, safe, and sustained use of medicines are the features of the journal, which has also been accepted for indexing on PubMed Central. The manuscript management system is completely online and includes a very quick and fair peer-review system, which is all easy to use. Visit http://www.dovepress.com/testimonials.php to read real quotes from published authors.

Submit your manuscript here: http://www.dovepress.com/drug-design-development-and-therapy-journal 